\title{
TRAVEL TIME PREDICTION MODELLING IN MIXED TRAFFIC CONDITIONS
}

\author{
Jaya Krishna Jammula ${ }^{1}$, Rajesh Bera ${ }^{2}$, Kodavanti Venkata Raghavendra Ravishankar ${ }^{3}$ \\ 1,2,3 Transportation Division, Department of Civil Engineering, National Institute of Technology, \\ Warangal-506004, Telangana, India
}

Received 13 September 2017; accepted 3 January 2018

\begin{abstract}
Over the past few decades, exponential increase in vehicle ownership resulted in issues of traffic control and management. Intelligent Transportation System (ITS) is one of the solutions for the intelligent management of traffic. ITS applications like Advanced Traveler Information Systems and Advanced Traffic Management Systems need travel time as a major input. The estimation of travel time in urban network became more complicated because of the rapid change in the system and traffic. This study is done in order to assess the impact of different travel modes on travel time. Data has been collected on a stretch of $14 \mathrm{~km}$ length in Warangal city, India using GPS probe vehicle along with video camera. Different private modes of transportation such as 2 wheeler, passenger car and 3 wheeler have been used as test vehicles for the collection of data in different traffic flow scenarios. Artificial Neural Network and a multi linear regression model have been developed to compare the estimated travel times with the field data. Two combinations of ANN model using single hidden layer, different numbers of neurons and epochs have been compared. The travel time of different modes has been compared and the effect of vehicle composition on travel time has been analyzed. The ANN model perform better than the regression model.
\end{abstract}

Keywords: travel time, ANN, GPS, regression, vehicle mode, mixed traffic.

\section{Introduction}

As the socioeconomic characteristics of people in the society changes with time and also the development of transport corridors are leading to a drastic change in the way of living of the people in urban as well as in rural regions. These changes in the people's daily life are resulting into increasing vehicle ownership at a faster rate. Private transport provides more convenience, comfort, safety when compared to public transport. As a result, public transportation usage decreases which means more private vehicle ply on the road and leading to elevated levels of congestion, environmental issues, accidents and other transportation issues. According to World Bank experts, the economic loss caused by congestion and poor roads alone is as high as $\$ 6$ billion a year in India (Vanajakshi et al., 2010). The allocation of road network (Fig. 1) is not compensating the increasing number of vehicle ownerships which poses a lot of problem in both traffic control and management system. In urban areas, there are restricted chances of expansion of the road network because of unavailability of road space.

${ }^{3}$ Corresponding author: ravikvr@nitw.ac.in 


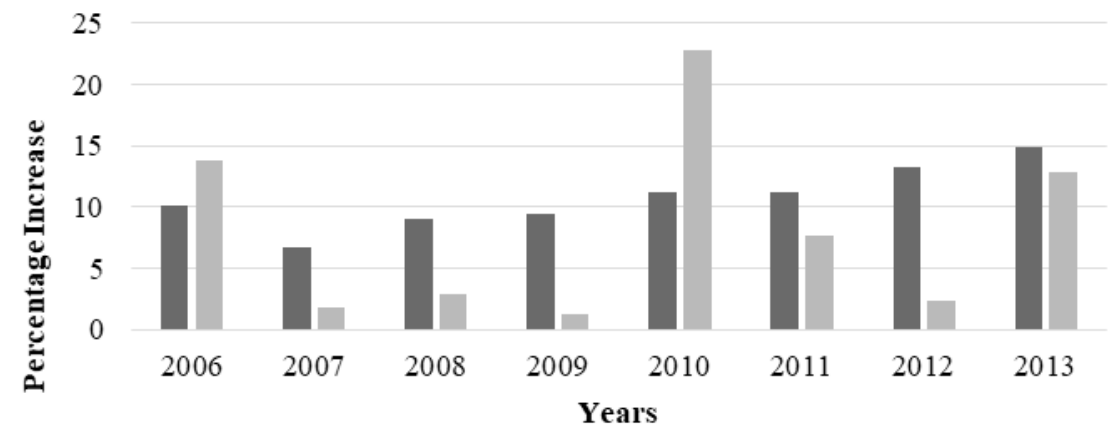

n Increase in Number of Vehicles $\quad$ Increase in urban roads

Fig 1.

Vehicle Ownership vs. Urban Roads Space Allocation (Guite, 2016)

In the area where expansion may not be possible, congestion can be overcome by manaing the traffic. Intelligent Transport Systems (ITS) have proved to be efficient way to reduce congestion in urban areas in developed countries. Two major components of the ITS are Advanced Traveler Information System (ATIS) and Advanced Transportation Management System (ATMS) which offers traveler real time traffic information that requires travel time as major input. Individual travelers make their trip decisions such as departure time, mode of travel, and path on the basis of familiarity with the road network as well as knowledge of the most likely travel time. From different data collection techniques available, GPS equipped probe vehicle is the best method to collect data as it requires less manpower and gives better accuracy (Takahashi and Izumi, 2009).

For modeling travel time for mixed traffic conditions, it is uncertain due to vehicle mode choice, lane changing etc. People may find the actual and predicted travel time using simple techniques varying very high. If travel time can be predicted more accurately before journey, it will be both effective and economical as well as this real time travel time information can be used for traffic management measures. The main objective of the study is to develop a travel time prediction model for mixed traffic conditions and determine the effect of mode of transportation on travel time.

\section{Review}

A brief review of some of the recent studies on travel time estimation on mixed traffic conditions is discussed below.

Studies have been done on real time bus arrival time prediction for Indian conditions by taking delay explicitly into account using Kalman Filtering using GPS probe vehicle (Padmanaban et al., 2010; Vanajakshi et al., 2008). A travel time prediction model has been using Resource Tracking and Management Service (RTMS) facility provided by mobile network provider (BSNL) on mobile SIMpassenger cards using buses as probes (Satyakumar et al., 
2014). Kalman filtering technique is used for prediction of travel time. The starting and arrival time at sections obtained from the cellular database were used to get the travel time and speed. Results obtained were statistically significant and it shows that use of mobile phone for travel time data collection is a low cost data collection technique. A bus travel time model was developed with the concept of total bus stop time (TBST) by considering all stopping times of bus like dwell time, stop time etc. and it proves better than previous models developed (Arhin et al., 2016).

A model based approach was developed to estimate traffic parameters (Flow, density, Travel time) using video camera and GPS. Lighthill - Witham - Richards (LWR) model and Exponential Speed-density relationship model were used and compared the results of these two (Kumar and Vanajakshi, 2014).

Amathematical model was developed for link travel time estimation using GPS probe vehicle using maximum continuous acceleration (MCA) and combined with average speed, they have set some fuzzy logic to incorporate the driving behavior into it. Though it fairly predicted the heterogeneity of travel time, it shows poor result for congestion and extremely slow moving vehicle ( $\mathrm{Li}$ and $\mathrm{McD}$ onald, 2002).

A probabilistic model (Expectation Maximization) was developed through arterial network using GPS probe vehicle for data collection and extracted travel time distributions from sparse noisy GPS (Hunter et al., 2007). The Expectation Maximization (EM) algorithm simultaneously learns the likely paths taken by the probe as well as travel time distributions through the network. A method was proposed for processing AVI travel time data from urban network and tested its applicability using automatic number plate recognition (ANPR) and video camera for data collection, while for fitting the model, they used Finite Mixture Models and EM algorithm (Kazagli and Koutsopoulos, 2013). This process can model the heterogeneity of travel time on freeways but high filtering requirement and applicability on urban conditions still not validated.

A three layer ANN model was developed and fitted into partial link travel time collected from GPS probe vehicles to estimate complete link travel time (Zheng and Zuylen, 2013). A link based ANN model for travel time prediction was proposed using a feed-forward network for training the network and logistic sigmoid function as activation function (Nahar and Sultana, 2014). A bus travel time prediction model was developed using Artificial Neural Network (ANN) model by taking dwell time, delays and distance between the bus stops as inputs (Amita et al., 2015). Model was developed, validated and tested using GPS (Global Positioning System) data collected from field study. Comparative study reveals that ANN model outperformed the regression model in terms of accuracy and robustness.

A study was conducted to check the applicability of smart mobile applications in transportation fields like safety, parking, travel information etc. (Siuhi and Mwakalonge, 2016). It suggests various mobile applications which can be used instead of high cost equipment. A mode specific travel time estimation model was developed by using Bluetooth detectors which gives similar data results as that of data from ANPR (Araghi et al., 2016). 
Most of the above studies were conducted under homogeneous traffic conditions. Few studies conducted in India, either car or bus is taken as probe vehicle whereas 2 wheeler and 3 wheeler vehicles occupy a major share of vehicle composition. Also the variation of travel time with respect to vehicle class is not studied. Hence the present study focus on mode specific travel time prediction in mixed traffic conditions.

\section{Study Area}

The present study is carried out to predict travel time in urban conditions and study the effect of different modes on travel time. As the travel time estimation has to be done in mixed traffic conditions, the corridor to be analyzed is selected on the basis of composition of traffic, types of intersection control (signalized and unsignalized). The selected route should be of great importance for both public and private transport modes and it should also contain all types of land uses.
By taking above mentioned criteria into consideration, corridor is selected from Warangal city in Telangana state, India. Warangal is linear city and also called as tricity (combination of Kazipet, Hanamkonda and Warangal). Corridor is selected from Kazipet railway station junction to Warangal bus station through Hanamkona CBD (central business district) as shown in the Fig. 2. This section joins two major railway stations and many other amenities via $\mathrm{NH}$ 163. It is approximately $14 \mathrm{Km}$ in length and consist of 14 major intersections out of which 6 are signalized and remaining are unsignalized.

The total road stretch is a 4 lane divided carriageway with various types of land uses on both sides. Traffic composition on the corridor for selected modes are about 2 wheeler-55\%, 3 wheeler- $25 \%$ and car$12 \%$ which represents good heterogeneous traffic conditions. Also this is major public transportation corridor in the city (plays most number of buses).

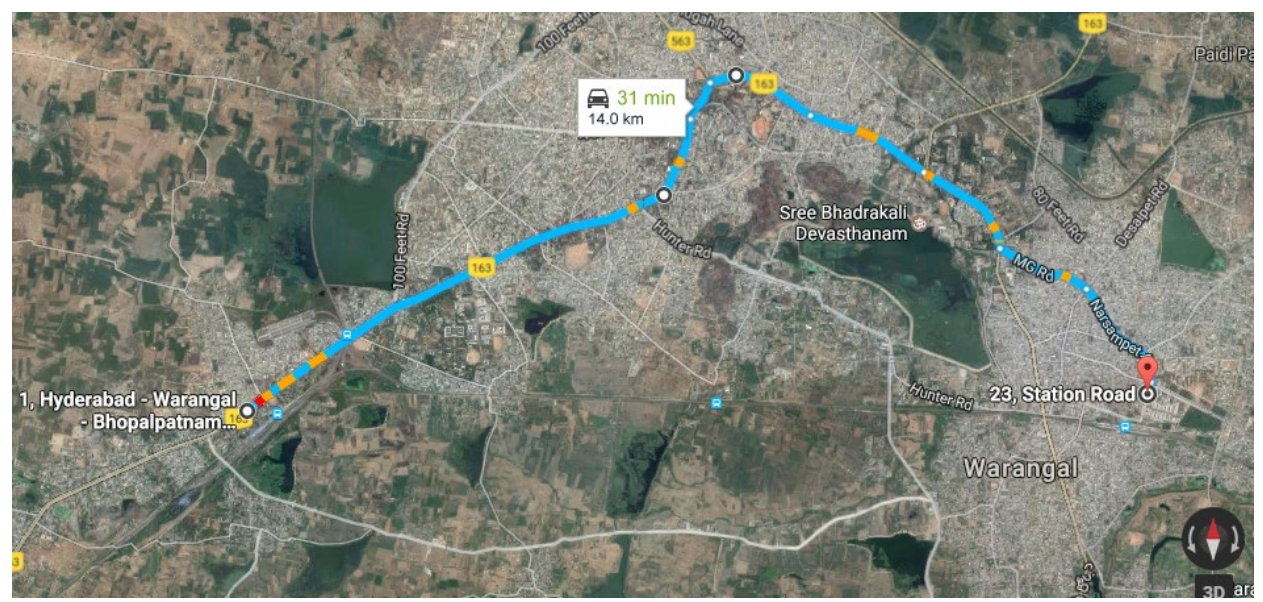

Fig 2.

Study Stretch (Google Map, 2017) 


\section{Data Collection and Analysis}

Data required for this purpose includes geometric data of the network, vehicular volume, intersection details and GPS data. Data is collected using two wheeler, passenger car, three wheeler because these classes of vehicles contributes major amount of traffic proportions in the study corridor. The data collected using GPS includes the latitude, longitude, Speed with time stamp of the vehicle at every logging interval.

For primary data i.e. volume and speed, video graphic survey and radar gun are used respectively. Intersection details and geometric details are collected manually.
Handheld GPS is carried with the vehicle to record the data.

As the study is to find out the travel time of a stretch so first of all the total stretch is divided into number of segments. From starting point onwards, each intersection to intersection is considered to be a segment or link. For calculating the link travel time, link volume has been calculated. The traffic flow will be different while moving from Kazipet to Warangal and to that of Warangal to Kazipet, so traffic volume count is done for both approaches. The video data collected from intersection has been extracted by counting the number of vehicles by video playback with reference to a line.

\section{Table 1}

List of Traffic Volumes (Kazipet to Warangal)

\begin{tabular}{|l|l|l|l|l|}
\hline \multirow{2}{*}{ Link Number } & \multicolumn{3}{|c|}{ Link Name } & \multicolumn{2}{c|}{ Traffic Volume (Veh/hr) (onward/backward) } \\
\cline { 3 - 5 } & & Peak & Intermediate & Off-peak \\
\hline 1 & Start-Kazipet & $1069 / 1518$ & $1054 / 1452$ & $411 / 393$ \\
\hline 2 & Kazipet - Fathima & $1448 / 1886$ & $1311 / 1742$ & $453 / 573$ \\
\hline 3 & Fathima - Forest & $2309 / 2019$ & $2044 / 1940$ & $374 / 531$ \\
\hline 4 & Forest - Collector & $2231 / 2664$ & $1989 / 2391$ & $489 / 660$ \\
\hline 5 & Collector - Spencers & $2584 / 2699$ & $2077 / 2473$ & $524 / 655$ \\
\hline 6 & Spencers - TMC & $2151 / 2393$ & $1948 / 2204$ & $648 / 840$ \\
\hline 7 & TMC - Ambedkar & $1548 / 1320$ & $1166 / 930$ & $583 / 775$ \\
\hline 8 & Ambedkar - Petrol & $2850 / 2943$ & $2270 / 2509$ & $682 / 480$ \\
\hline 9 & Petrol - Ashoka & $3123 / 3269$ & $2525 / 2858$ & $504 / 792$ \\
\hline 10 & Ashoka - Mulugu & $3036 / 3852$ & $2927 / 3751$ & $548 / 622$ \\
\hline 11 & Mulugu - MGM & $4064 / 3949$ & $3955 / 3869$ & $528 / 648$ \\
\hline 12 & MGM - RDR & $2659 / 2737$ & $2598 / 2482$ & $532 / 612$ \\
\hline 13 & RDR - Kasibugga & $2256 / 1755$ & $2193 / 1659$ & $472 / 610$ \\
\hline 14 & Kasibugga - Narsampet & $1646 / 1405$ & $1440 / 1337$ & $415 / 396$ \\
\hline 15 & Narsampet - End Point & $823 / 1029$ & $663 / 931$ & $372 / 324$ \\
\hline
\end{tabular}

It has been clearly observed from the above Table 1 that off-peak period flow is significantly lower than normal flow condition while peak flow traffic is not that much varying compared to normal flow condition for most of the links. The vehicle compositions at peak, intermediate and offpeak conditions are as shown in Fig. 3. 


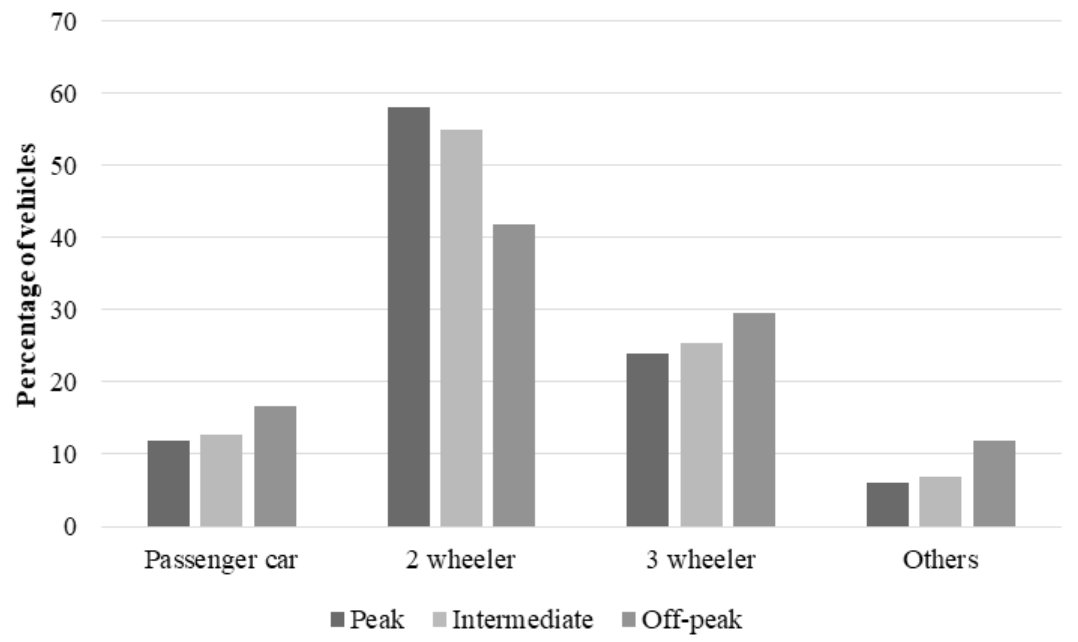

Fig 3.

Vehicle Compositions in Different Traffic Flow Conditions

It has been observed that the 2 wheeler is having a significant share when compared to all other modes. The share of 2 wheeler is more at peak and intermediate flow conditions while it comes down at off-peak flow condition. The peak hour, off-peak period and intermediate flow condition has been found out based on the volume count. Peak flow condition is obtained between $5: 15 \mathrm{pm}$ to $6: 15 \mathrm{pm}$, intermediate condition between 10:15am to 11:15am and off peak is taken between 5:00am to 6:00am.

Each vehicle comprised of a research member with a GPS device and video camera. All 3 modes will start simultaneously from the starting point. After reaching the end point, they will wait for the remaining test vehicles to reach them and again they will repeat the same for the time period mentioned above.

The raw data set records the latitude, longitude, elevation, speed, track time, compass heading, and accuracy level at each 1 second interval. The data has been converted to use as input. The location data for two consecutive logging intervals has been used to obtain the geographical distance covered by the mode for that interval. The distance covered has been calculated using the Haversine formula. The track time has been customized to get the time difference between two logging interval in seconds and this is useful to find out the error while logging interval i.e. more than 1 second logging interval as well as to find out the total travel time. The intersections has been identified at the Google map in terms of positions and noted down. The raw data sets obtained after the modifications has been matched with the known intersection positions available, to find out the actual intersections positions for those data sets. The positions where speeds are zero have been identified and matched with the video timing to find out whether a queue had been formed. If the queue had been formed then the queue length has been calculated. The average speed, distance between the intersections has been calculated and queue length has been taken as a separate 
input variable. The volume data has been converted into lane volume by dividing the link volume by the number of lanes for that link. The signal timings have been calculated using a stopwatch. The final input data set is as shown below in Table 2 .

Table 2

Total Input Parameters Considered for Model Development

\begin{tabular}{|l|l|l|l|l|l|l|l|l|l|}
\hline $\begin{array}{c}\text { Total Volume } \\
(\mathbf{v e h} / \mathbf{h r} / \mathbf{l a n e})\end{array}$ & $\begin{array}{c}\text { \% of } \\
\text { Vehicular } \\
\text { Class } \mathbf{( \% )}\end{array}$ & $\begin{array}{c}\text { Total } \\
\text { Distance } \\
(\mathbf{m})\end{array}$ & $\begin{array}{c}\text { Average } \\
\text { Speed } \\
(\mathbf{m} / \mathbf{s})\end{array}$ & $\begin{array}{c}\text { Queue } \\
\text { Length } \\
(\mathbf{m})\end{array}$ & $\begin{array}{c}\text { Signal } \\
\text { Time } \\
(\mathbf{s e c})\end{array}$ & $\begin{array}{c}\text { Green } \\
\text { Time } \\
(\mathbf{s e c})\end{array}$ & $\begin{array}{c}\text { Red } \\
\text { Time } \\
(\mathbf{s e c})\end{array}$ & $\begin{array}{c}\text { Stopping } \\
\text { Time } \\
(\mathbf{s e c})\end{array}$ & $\begin{array}{c}\text { Total } \\
\text { Time } \\
(\mathbf{s e c})\end{array}$ \\
\hline 527 & 20.0 & 145.0 & 15.2 & 0.0 & 125 & 40 & 85 & 0 & 31 \\
\hline 656 & 18.8 & 1853.2 & 32.1 & 0.0 & 0 & 0 & 0 & 0 & 209 \\
\hline 1022 & 10.7 & 1916.9 & 37.8 & 0.0 & 0 & 0 & 0 & 0 & 183 \\
\hline 974 & 17.6 & 363.6 & 29.9 & 0.0 & 0 & 0 & 0 & 0 & 43 \\
\hline 583 & 8.9 & 1049.5 & 32.8 & 0.0 & 0 & 0 & 0 & 0 & 116 \\
\hline 1135 & 14.1 & 414.8 & 14.1 & 32.8 & 96 & 33 & 63 & 35 & 106 \\
\hline 1263 & 11.1 & 1032.8 & 18.0 & 0.0 & 0 & 0 & 0 & 0 & 198 \\
\hline 1464 & 8.3 & 1868.6 & 21.3 & 37.4 & 90 & 40 & 50 & 30 & 312 \\
\hline 1978 & 9.9 & 1340.4 & 31.4 & 0.0 & 0 & 0 & 0 & 0 & 151 \\
\hline 1299 & 7.0 & 1161.3 & 18.4 & 27.9 & 120 & 40 & 80 & 68 & 225 \\
\hline 1022 & 10.7 & 1916.4 & 42.2 & 0.0 & 0 & 0 & 0 & 0 & 162 \\
\hline 995 & 10.3 & 390.2 & 29.6 & 0.0 & 0 & 0 & 0 & 0 & 45 \\
\hline 1039 & 36.4 & 855.4 & 21.6 & 59.3 & 90 & 35 & 55 & 26 & 142 \\
\hline 974 & 35.2 & 366.8 & 24.5 & 0.0 & 0 & 0 & 0 & 0 & 53 \\
\hline
\end{tabular}

The travel time data obtained from all the journey time of all three modes on aggregate different modes has been compared. The has been compared as shown below in Fig. 4 .

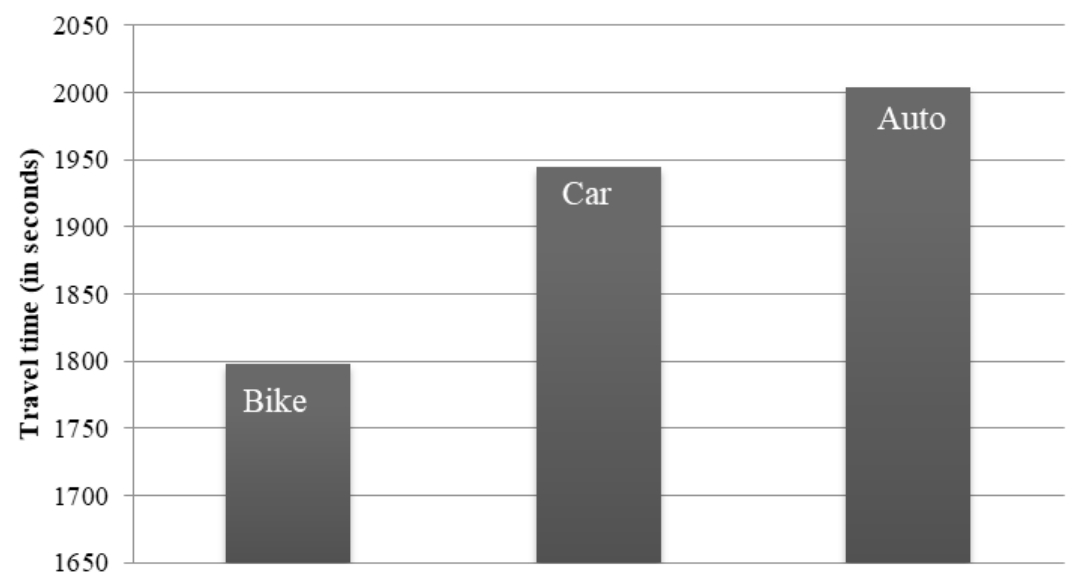

Vehicle mode

Fig 4.

Average Journey Time of all Three Modes 
It has been clearly observed that the journey time for 2 wheeler is less than passenger car than that of 3 wheeler which indicates the lane changing for 2 wheeler is more during medium or peak traffic condition. During off-peak condition, passenger car has less travel time as it moves with speed greater than 2 wheeler.

\section{Model Development}

Travel time in urban arterials is complex in nature and is influenced by many parameters. This section presents mathematical relationship developed between the influencing parameters and travel time values. The influencing parameters that are considered for modeling are volume per lane, percentage of vehicle classes, distance covered, average speed, queue length, red time and stopping time. The parameters are analyzed first to understand the effect of each parameter on travel time and the relations of each parameter. The correlations between each independent variable have been found out. The multiple linear regression (MLR) method and artificial neural network (ANN) has been used for model preparation. The MLR model has been adopted because of its simplicity and applicability in any conditions. The non-linearity of the data set cannot be modeled using MLR and requires more complex algorithm like ANN which in turn has better prediction accuracy. The model development using both of them are explained below.

\subsection{Multiple Linear Regression Model}

It is observed from the correlation table that total distance is the most influencing parameter out of the others. The other parameters are also showing medium to low correlation with the travel time.

The development of the model has been done using $70 \%$ of the total data set whereas the testing has been done using the rest 30\% data. The step wise regression analysis has been done in SPSS with intercept value is as shown below in Table 3 .

\section{Table 3}

Model Summary with Intercept

\begin{tabular}{|l|l|l|l|l|}
\hline \multicolumn{1}{|c|}{ Model } & \multicolumn{1}{|c|}{$\mathbf{R}$} & \multicolumn{1}{|c|}{$\mathbf{R}^{2}$} & \multicolumn{1}{|c|}{ Adjusted $\mathbf{R}^{2}$} & \multicolumn{1}{c|}{$\begin{array}{c}\text { Std. Error of the } \\
\text { Estimate }\end{array}$} \\
\hline 1 & $0.819 \mathrm{a}$ & 0.670 & 0.670 & 46.29 \\
\hline 2 & $0.938 \mathrm{~b}$ & 0.880 & 0.880 & 27.93 \\
\hline 3 & $0.954 \mathrm{c}$ & 0.911 & 0.911 & 24.09 \\
\hline 4 & $0.956 \mathrm{~d}$ & 0.915 & 0.914 & 23.58 \\
\hline 5 & $0.958 \mathrm{e}$ & 0.917 & 0.917 & 23.24 \\
\hline 6 & $0.958 \mathrm{f}$ & 0.918 & 0.917 & 23.19 \\
\hline
\end{tabular}

Where:

Predictors: (Constant), Total Distance;

Predictors: (Constant), Total Distance, Average Speed;

Predictors: (Constant), Total Distance, Average Speed, Red Time;

Predictors: (Constant), Total Distance, Average Speed, Red Time, Volume;

Predictors: (Constant), Total Distance, Average Speed, Red Time, Volume, \% of Class;

Predictors: (Constant), Total Distance, Average Speed, Red Time, Volume, \% of Class, Queue Length. 
It is observed from the above table that six variables are giving significant results while doing regression analysis. The parameter stopping time has been excluded from the original input parameter as it has insignificant effect on the model.

Four models have been developed using regression analysis by considering all parameters and excluding stopping time, each with and without intercept. The four models developed has been compared as shown in Table 4.
The model 1 is having better performance in terms of percentage of error. The intercept value is 67.49 which do not have any practical implications so it can be written as Eq. (1):

$\mathrm{TT}=0.115 \cdot \mathrm{d}-8.703 \cdot \mathrm{v}+0.756 \cdot \mathrm{r}+0.014 \cdot \mathrm{q}-0.253 \cdot \mathrm{c}+0.164 \cdot \mathrm{l}$

Where $\mathrm{TT}=$ travel time, $d=$ total distance, $v=$ average speed, $r=$ red time, $q=$ volume, $c=\%$ of class, $l=$ queue length. Model has been validated for the data on last day of survey. The MAPE value using Regression model is 16.80 which is satisfactory.

Table 4

Comparison of Different Models

\begin{tabular}{|l|l|l|l|l|l|l|}
\hline Model & \multicolumn{1}{|c|}{ Parameters } & $\begin{array}{l}\text { p-Value and } \\
\text { t-Value }\end{array}$ & Logic & \multicolumn{1}{|c|}{ R $^{2}$} & MAPE & RMSE \\
\hline Model 1 & $\begin{array}{l}\text { Intercept, Total Distance, Average Speed, Red Time, } \\
\text { Volume, \% of Class, Queue Length }\end{array}$ & Satisfied & Correct & 0.918 & 16.80 & 18.30 \\
\hline Model 2 & $\begin{array}{l}\text { Total Distance, Volume, Average Speed, Queue } \\
\text { Length, Red Time, \% of Class }\end{array}$ & Satisfied & Correct & 0.963 & 20.81 & 22.24 \\
\hline Model 3 & $\begin{array}{l}\text { Intercept, Total Distance, Average Speed, Stopping } \\
\text { Time, Volume, \% of Class, Queue Length, Red Time }\end{array}$ & Not satisfied & $\begin{array}{l}\text { Not } \\
\text { correct }\end{array}$ & 0.962 & 20.88 & 22.44 \\
\hline Model 4 & $\begin{array}{l}\text { Total Distance, Average Speed, Stopping Time, } \\
\text { Volume, \% of Class, Queue Length, Red Time }\end{array}$ & Not satisfied & Correct & 0.962 & 20.88 & 22.44 \\
\hline
\end{tabular}

Note: MAPE: mean absolute percentage error; RMSE: root mean square error.

The model is only valid for travel time greater than 67.49 seconds. This can be inferred that the model will work for medium and long sections which have on an average travel time greater than 67.49 seconds. An ANN model has been developed to overcome the problem with regression model.

\subsection{Network Development}

Machine learning methods like artificial neural network (ANN) can deal with very complex relationships between predictors that can arise from large amount of data with lots of parameters and greater amount of noise in the data set. These models can be used for estimation of travel time without explicitly taken into account the traffic process (physical). ANN can easily learn from some given examples and model subtle relationship between variables even though practically their relationship is very hard to explain. Thus ANN can be conveniently used for problems whose solutions require knowledge that is hard to specify. However to obtain maximum accuracy from the developed model the data set has to be sufficiently large (Zhang et al., 1998).The solutions of ANN are location specific and it cannot be transferable to the other locations due to location-specific conditions.

For building a neural network there is no generalized procedure it is basically a trial 
and error approach. There are mainly three types of data set is required for building and evaluating a network. Those are training data, testing data and validation data. From the runs conducted using different modes with mobile application total 1664 data points are extracted, out of this data sets $25 \%$ is used for validation and from remaining $75 \%, 70 \%$ has been used as a training data and $30 \%$ has been used as testing data. The data collected from another location has been used for validation of the developed model. MATLAB (R2013a) version 8.1.0.430 has been used for neural network development. It has been already explained that development of neural network is a trial and error function. So two combinations, model 1 using trainbfg and model 2 using trainlm functions are used as training functions with learngdm as adaptive function and transig-purelin as transfer function. First to fix number of hidden layers single and double hidden layer has been used for same number of neurons and iterations. 1000 epochs are used in either case. The error percentage using trainlm function for different number of neurons has been shown in Table 5. It can be observed that single hidden layer is giving better results compared to double hidden layer. It can also be observed that with less numbers of neurons the performance is quite similar but with increasing numbers of neurons the single layer quite clearly out performs the double hidden layer. One single hidden layer is enough to model the non-linearity of the data and due to the fact in mind of the problem of complexity and over fitting of the data only single hidden layer has been used for this present study.

\section{Table 5}

Comparison of Hidden Layers for Trainlm

\begin{tabular}{|c|c|c|}
\hline \multirow{2}{*}{ Neurons } & \multicolumn{2}{|c|}{ MAPE (\%) } \\
\hline & Single Hidden Layer & Double Hidden Layer \\
\hline 2 & 5.74 & 5.01 \\
\hline 3 & 5.38 & 5.45 \\
\hline 4 & 6.45 & 5.35 \\
\hline 5 & 4.60 & 5.66 \\
\hline 6 & 5.44 & 6.32 \\
\hline 7 & 5.78 & 8.00 \\
\hline 8 & 6.39 & 5.66 \\
\hline 9 & 5.43 & 6.89 \\
\hline 10 & 4.80 & 16.00 \\
\hline 15 & 5.79 & 15.60 \\
\hline 20 & 6.87 & 89.35 \\
\hline
\end{tabular}

It can be seen from the above table5that the error value is lowest for 5 numbers of neurons. While after adding 10 neurons the error percentage is steeply increasing. The numbers of epochs are next changed for 5 numbers of neurons to get the optimum number of epochs. It can be observed that the performance value is not changing heavily after certain number of epochs compare to the trainlm function. Similarly trainbfg function is also checked.

The trainlm function and learngdm function when used at a time there is chance of over fitting but as the number of parameters are much smaller than the number of points in the training data set, there is little chance of over fitting. 


\subsection{Comparison of Two ANN Models}

The model using two combinations has been compared with respect to different parameters and is tabulated as below.

Table 6

Comparison of Two Models

\begin{tabular}{|l|l|l|}
\hline \multicolumn{1}{|c|}{ Parameter } & \multicolumn{1}{c|}{ Model 1 } & \multicolumn{1}{c|}{ Model 2 } \\
\hline Training Function & Trainlm & Trainbfg \\
\hline Layer 1 Transfer function & Tansig & Tansig \\
\hline Layer 2 Transfer function & Purelin & Purelin \\
\hline Adaptation Function & learngdm & learngdm \\
\hline Neurons & 5 & 7 \\
\hline No. of Hidden Layers & 1 & 1 \\
\hline No. of Epochs & 88 & 1500 \\
\hline MAPE & 4.58 & 5.08 \\
\hline R Value & 0.99 & 0.99 \\
\hline P -value & 0.02 & 0.00 \\
\hline t-test tabulated & 1.96 & 1.96 \\
\hline t -value & 2.32 & 3.78 \\
\hline DOF & 596 & 596 \\
\hline Null hypothesis & Accepted & Accepted \\
\hline
\end{tabular}

It can be inferred that two functions almost performs equally well under given circumstances but due to faster convergence and better performance value trainlm is performing better than trainbfg function.

The $t$-test value of both the models has been showing that there is no significant difference between the mean values of the two data sets i.e. the predicted and observed value. The $\mathrm{t}$-value and $\mathrm{p}$-value both are satisfied for both the models. The $\mathrm{R}$ value of Model1 is slightly better than that of Model 2 .

\subsection{Comparison of Regression and ANN model}

The best model for ANN is obtained using trainlm as a training function. So for comparison of ANN and regression models, trainlim training function is used. The comparison of the same is tabulated in Table 7.

Table 7

Comparison between Regression and ANN Models

\begin{tabular}{|l|l|l|}
\hline \multicolumn{1}{|c|}{ Parameter } & \multicolumn{1}{c|}{$\mathbf{1}$} & \multicolumn{1}{c|}{$\mathbf{2}$} \\
\hline Network & ANN & Regression \\
\hline Number of parameters & 6 & 6 \\
\hline MAPE & 4.58 & 16.80 \\
\hline $\mathrm{R}^{2}$ & 0.99 & 0.96 \\
\hline
\end{tabular}

It can be clearly observed that neural network model better predicts the travel time than regression function for the same number of input parameters. The relation of travel time with \% of vehicle class using regression function is as shown in Fig. 5. It 
can be seen that the travel time is decreasing with increase in $\%$ of vehicle class. As the vehicle composition is approaching more homogeneous flow, the predicted travel time is lesser than that of the corresponding mixed traffic flow.

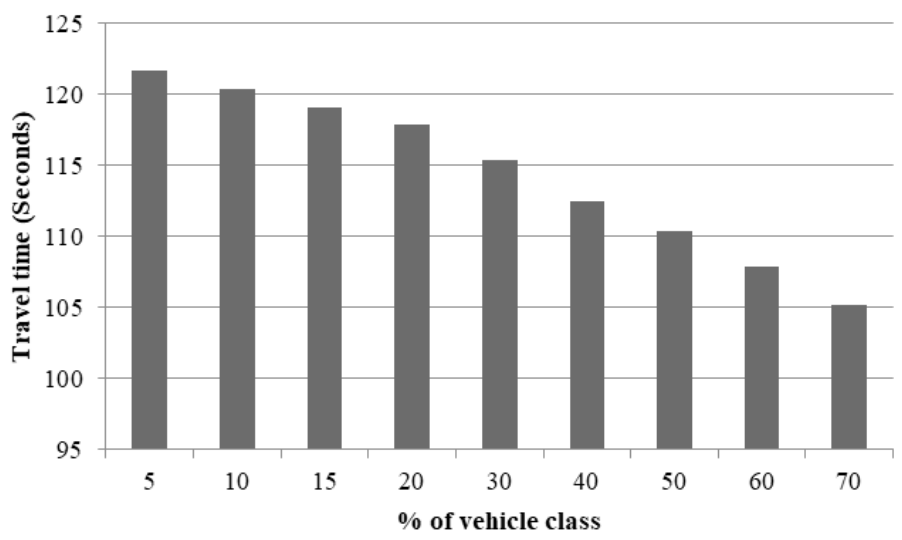

Fig 5.

Variation of Travel time with \% of vehicle class using Regression

\section{Conclusions}

The paper mainly focuses on the use of artificial neural network and application of regression models for travel time prediction. The application of travel time prediction modeling is huge as it has been already implemented for bus travel time prediction. So, if private transportation also can be provided with such kind of facilities, the travel time cost will come down. This was the main motivation for this work. In this study along with the development of model, the impact of vehicle class is also explored. The comparison of the results and validation shows quite satisfactory results.

From this study, it can be concluded that average stopped time while making journey has been more for passenger car than that of 2 wheeler than that of 3 wheeler. Travel time of passenger car will be less compared to 3 wheeler if the section length is increased while for shorter section passenger car travel time is more compared to others. The section wise travel time of 2 wheeler is less compared to other modes whereas apart from the off-peak period the journey time using passenger car and 3 wheeler fluctuates very significantly from link to link. The MAPE value for regression model is obtained as 16.80 and that for ANN is obtained as 4.59. So, ANN model outperforms the regression model. Percentage class is a very significant parameter for travel time estimation and its showing that for higher the percentage of vehicle class, lesser travel time is predicted. It can be concluded that the mode of transportation is an important factor to be considered while predicting travel time in mixed traffic conditions as it shows significant effect on travel time.

The various access points and median 
openings alongside the road have not been considered in this study which will affect the travel time. Effect of driver behaviour on travel time is not considered.

\section{References}

Amita, J.; Singh, J.; Kumar, G. 2015. Prediction of Bus Travel Time Using Artificial Neural Network, International Journal for Traffic and Transport Engineering 5(4): 410-424.

Araghi, B.N.; Krishnan, R.; Lahrmann, H. 2016. Mode-specific travel time estimation using Bluetooth technology, Journal of Intelligent Transportation Systems 20(3): 219-228.

Arhin, S.; Noel, E.; Anderson, M.F.; Williams, L.; Ribisso, A.; Stinson, R. 2016. Optimization of transit total bus stop time models, Journal of traffic and transportation engineering (English edition) 3(2): 146-153.

Guite, K. 2016. Total number of registered vehicles in India. Available from internet: <https://data.gov.in/ catalog/total-number-registered-motor-vehicles-india $>$.

Hunter, T.; Herring, R.; Abbeel, P.; Bayen, A. 2007. Path and travel time inference from GPS probe vehicle data, NIPS Analyzing Networks and Learning with Graphs 12(1): 8p.

Kazagli, E.; Koutsopoulos, H.N. 2013. Estimation of Arterial Travel Time from Automatic Number Plate Recognition Data, Journal of the Transportation Research Board 2391: 22-31.

Kumar, S.V.; Vanajakshi, L. 2014. Urban Arterial Travel Time Estimation Using Buses as Probes, Arabian Journal for Science \& Engineering 39: 7555-7567.

Li, Y.; McDonald, M. 2002. Link Travel Time Estimation Using Single GPS Equipped Probe Vehicle. In Proceedings of the IEEE $5^{\text {th }}$ International Conference on Intelligent Transportation Systems, 932-937.
Nahar, L.; Sultana, Z. 2014. A New Travel Time Prediction Method for Intelligent Transportation System, Journal of Computer Engineering 16(3): 24-30.

Padmanaban, R.P.S.; Divakar, K.; Vanajakshi, L.; Subramanian, S.C. 2010. Development of a real-time bus arrival prediction system for Indian traffic conditions, IET Intelligent Transport Systems 4(3): 189-200.

Satyakumar, M.; Anil, R.; Sivakumar, B. 2014. Travel Time Estimation and Prediction using Mobile Phones: A Cost Effective Method for Developing Countries, Civil Engineering Dimension 16(1): 33-39.

Siuhi, S.; Mwakalonge, J. 2016. Opportunities and challenges of smart mobile applications in transportation, Journal of traffic and transportation engineering (English edition) 3(6): 582-592.

Takahashi, S.; Izumi, T. 2009. Application of Genetic Algorithm to Travel Time Measurement Using Vehicle Data Provided from Ultrasonic vehicle Detectors, Electronics and Communications in Japan 92(8): 43-52.

Vanajakshi, L.; Ramadurai, G.; Anand. A. 2010. Intelligent Transport Systems: Synthesis report on ITS including issues and challenges in India. Available from internet: <https://coeut.iitm.ac.in/ITS_synthesis. pdf $>$.

Vanajakshi, L.; Subramanian. S.C.; Sivanandan. R. 2008. Travel time prediction under heterogeneous traffic conditions using global positioning system data from buses, IET Intelligent Transport Systems 3(1): 1-9.

Zhang, G.; Patuwo, B.E.; Hu, M.Y. 1998. Forecasting with artificial neural networks: The state of the art report, International Journal of Forecasting 14(1): 35-62.

Zheng, F.; Zuylen, H. 2013. Urban link travel time estimation based on sparse probe vehicle data, Transportation Research Part C: Emerging Technologies 31: 145-157. 